\title{
Editorial
}

\section{Editorial: Mentoring Graduate Students}

\author{
Betul C. Czerkawski \\ Editor, ITET
}

\author{
Eugene W. Lyman \\ Managing Editor, ITET
}

\begin{abstract}
Digital scholarship is rapidly transforming the traditional mentoring relationship between faculty members and graduate students. ITET seeks to assist in this transition by providing a forum for graduate students and newer faculty members.
\end{abstract}

Keywords: editorial; faculty mentoring; digital scholarship; graduate students

The role of faculty members in the preparation of graduate students as future intellectual leaders and potential colleagues both within and outside of academia is undeniable. Faculty members teach graduate courses, advise students and direct dissertation committees. But as new digital technologies change academic life, this mentor-mentee relationship is also changing. As older forms dissolve, or become less common, it's worth asking: what forms an effective mentor-mentee relationship in $21^{\text {st }}$ century academia?

A minimal definition of mentoring is simple advising of academic progress in students' degree programs. Graduate students, however, rightly expect more from their advisors. The key to effective mentoring is for advisors to take a genuine interest in students' professional goals and to help them develop a realistic agenda for their future careers. Ideally, this would include investing time in getting to know one's advisees beyond the classroom environment, understanding their career aspirations, respecting their diverse needs, learning their styles and motivation, and guiding them as they develop expertise in their content areas. There is already a good deal of literature on effective practices for mentors and mentees; our focus here, however, is on this relationship in light of the changing nature of scholarship due to recent technological developments.

There are two important aspects of digital scholarship that relate to the mentor/mentee relationship: First, in the $21^{\text {st }}$ century, college professors are no longer the gatekeepers of knowledge -the lines between academic disciplines have blurred; as a consequence of the 'information explosion' new internet-based communication channels and opportunities for networking are available to students at all levels. Thus many former elements of graduate student mentoring (shadowing, simple observation, etc.) are no longer as effective for students developing their own scholarship. 
Second, recent graduate students have more diverse backgrounds and interests. They may have full time jobs and families, and therefore prefer online courses that accommodate their busy schedules. In almost all cases, they are comfortable with technology-based communications. Additionally, they have access to a wide range of information sources in their chosen disciplines and are more experienced in making sense of the complex data sets these sources provide. We have noted that more and more universities hire academic advisors (not necessarily faculty members) who can keep track of these students and their academic progress.

While these changes do not necessarily eliminate the need for mentoring, they do require new approaches both from students and professors. Graduate students still need to learn to identify and utilize relevant and high quality information sources as well as develop metacognitive skills to manage their own learning. Additionally, it is still important and useful actually to shadow expert learners as they perform essential scholarly activities such as writing, applying for grants, conducting research and negotiating professional networks.

On the other hand, professors need to continue to engage in an active scholarship, take an active interest in their students' careers, and be fully aware of the opportunities offered by new technologies. This will enable them to customize their mentoring styles and adjust to the blurring lines between formal and informal education.

ITET provides a special forum for those graduate students who are in the process of developing their scholarship. We invite all readers to send commentaries or critiques that will help further these students' work. In addition to our graduate student section, you will also see other authors who are co-conducting research with their mentors, or new faculty members establishing their own research agenda or conducting their early individual studies.

Please join the discussion by sending your reviews, critiques and commentaries that will positively contribute to these new scholars' development as new professionals. 